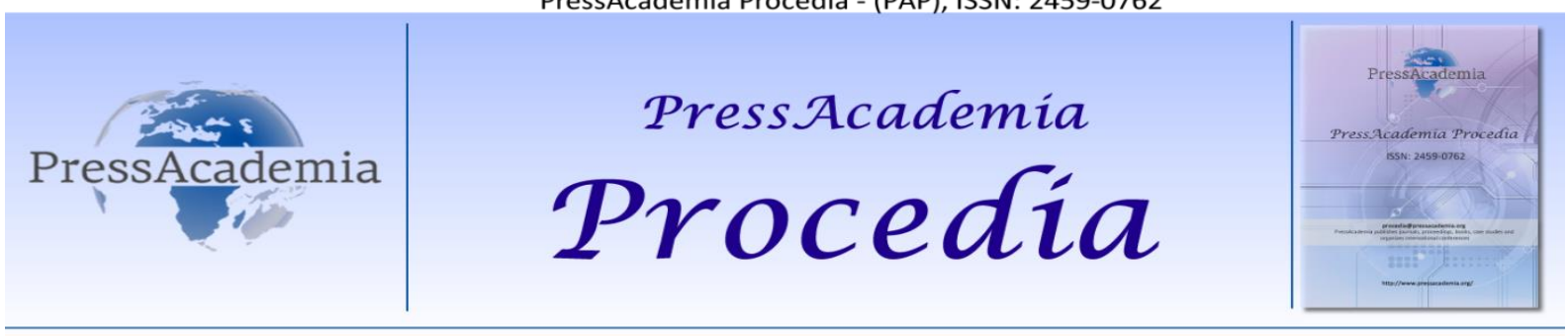

Global Business Research Congress (GBRC), May 24-25, 2017, Istanbul, Turkey

\title{
THE EFFECT OF SATISFACTION FROM AFTER-SALES SERVICES PROVIDED IN AUTHORIZED AUTOMOBILE SERVICES ON RECOMMENDATIONS TO OTHER CUSTOMERS
}

\section{DOI: 10.17261/Pressacademia.2017.645 \\ PAP- GBRC-V.3-2017(71)-p.691-696}

Onder Kethuda ${ }^{1}$, Suleyman Agras ${ }^{2}$, Oznur Karayel $^{3}$

${ }_{1}^{1}$ Duzce University, Akcakoca School of Tourism and Hotel Management, Duzce, Turkey. onderkethuda@duzce.edu.tr

${ }^{2}$ Duzce University, Akcakoca School of Tourism and Hotel Management, Duzce, Turkey. suleyman.agras@duzce.edu.tr

${ }^{3}$ Duzce University, Social Sciences Institute, Duzce, Turkey. oznurkryl@gmail.com

\section{To cite this document}

Kethuda, O., S. Agras and O. Karayel (2017). Effect of satisfaction from after-sales services provided in authorized automobile services on recommendations to other customers. PressAcademia Procedia (PAP), V.3, p.691-696.

Permemant link to this document: http://doi.org/10.17261/Pressacademia.2017.645

Copyright: Published by PressAcademia and limited licenced re-use rights only.

\section{ABSTRACT}

The purpose of this research is to identify the effects of satisfaction from after-sales services components in authorized automobile services on recommendation behaviors to other customers. The research is designed based on quantitative methods. The population of research consists of the customers who get services from authorized automobile services (HASMER) in Duzce. The data have been collected by questionnaire form. It has collaborated with authorized automobile service to discover the components of service and developing a scale for measuring those service components. The obtained data have been analyzed by using AMOS and SPSS. The results of this research show that the most effective factors affecting recommendations behaviors of costumers are satisfaction level from staff-customer interaction, maintenance service and not changing the initial price offered to customers. Based on the results, authorized automobile services are strongly recommended to identify the cost items clearly in the beginning of the maintenance process and not to increase it when the work is done. Furthermore, authorized automobile services are strongly advised to employ the staffs who are experienced in maintenance, and have good-humored and communicative personality.

Keywords: Satisfaction, recommendation, after-sales services, maintenance, authorized automobile service. JEL Codes: M3, M30, M31

\section{OTOMOBIL YETKILI SERVISLERINDE SUNULAN SATIŞ SONRASI HIZMETLERDEN MEMNUNIYETIN BAŞKALARINA TAVSIYE ÜZERINDEKI ETKISI}

\section{ÖZET}

Bu araştırmanın amacı, otomobil yetkili servislerinde sunulan satış sonrası hizmet bileşenlerinden memnuniyetin başkalarına tavsiye etme davranışı üzerindeki etkisini belirlemektir. Araştırma nicel araştırma yöntemine göre tasarlanmıştır. Araştırmanın evrenini Düzce'de bulunan bir otomobil yetkili servisinden (HASMER) hizmet alan müşteriler oluşturmaktadır. Araştırma kapsamında veriler anket yöntemiyle toplanmıştır. Otomobil yetkili servislerindeki hizmet bileşenlerinin belirlenmesi ve bu bileşenlere ilişkin ölçeğin geliştirme süreçlerinde, otomobil yetkili servisiyle iş birliğine gidilmiştir. Elde edilen veriler, AMOS ve SPSS ile analiz edilmiştir. Araştırma sonucuna göre, müşteri danışmanı, bakım onarım hizmeti ve başlangıçta verilen fiyata sadık kalma başkalarına tavsiye etme davranışını en çok etkileyen faktörlerdir. Otomobil yetkili servislerine, özellikle başlangıçta fiyat verirken bütün masraf kalemlerini net olarak belirlemeleri ve araç tesliminde bu fiyata sadık kalmaları tavsiye edilmektedir. Ayrıca, otomobil yetkili servislerine, bakım onarımla ilgili uzmanlığı olan, güler yüzlü ve yardımcı olmaya istekli kişileri müşteri danışmanı olarak çalıştırmaları tavsiye edilmektedir.

Anahtar Kelimeler: Memnuniyet, başkalarına tavsiye, satış sonrası hizmetler, bakım-onarım, otomobil yetkili servisi. JEL Kodları: M3, M30, M31 


\section{GiRiş}

Otomobil yetkili servislerinde verilen bakım onarım hizmetleri, teknik bilgi gerektiren hizmetlerdir. Otomotiv sektörü gibi teknik bilgi gerektiren konularda genellikle, müşteriler tarafından algılanan risk yüksektir (Özbek, 2016). Algılanan risk, tüketicilerin satın alma kararlarının sonuçlarına ilişkin belirsizlik algısı olarak tanımlanmakta (Yee ve diğ, 2011) ve bu öngörebilme düzeyiyle ters orantılı olarak artmaktadır (Sweeney ve diğ., 1999). Otomotiv sektöründe yapılan algılanan risk, algılanan değer ve hizmet kalitesini inceleyen çalışmaların ((Yee ve diğ,, 2011; Özbek, 2016) yanında, otomobil yetkili servislerinden sunulan hizmet kalitesi ve bu hizmetlerden memnuniyete ilişkin çalışmalar da literatürde mevcuttur (Bengül, 2006; Güllülü ve Bilgili, 2011; Özgüner ve Kurtuldu, 2015). Bunun yanında, hizmet bileşenlerinden memnuniyet düzeyinin başkalarına tavsiye etme davranışı üzerindeki etkisini araştıran çalışmaya literatürde rastlanmamıştır. Müşterilerin risk algısının yüksek olduğu hizmetlerde, o hizmetten geçmişte faydalanan diğer müşterilerin tavsiyesi, müşteri karar verme sürecinde çok etkilidir. Bu nedenle, otomobil yetkili servislerinin hangi müşteriler tarafından başkalarına tavsiye edildiğinin belirlenmesi gerek bu hizmeti sunan ve gerekse satın alan taraflar açısından önemlidir. Başkalarına tavsiye etme, genellikle, aldığı hizmettin bileşenlerinden memnun olan kişiler tarafından gerçekleştirilmektedir. Bununla birlikte, otomobil yetkili servislerinde sunulan hizmetin her bir bileşeninden memnuniyetin başkalarına tavsiye davranışını üzerindeki etkisi bilinmemektedir. Bu çerçevede bu araştırmanın amacı, otomobil yetkili servislerinde sunulan hizmet bileşenlerinden memnuniyet düzeyinin başkalarına tavsiye etme davranışı üzerindeki etkisini belirlemektir.

\section{LITERATÜR INCELEMESi}

Otomobil yetkili servisleri, otomobil firmasının adına belirlenen şartlara göre bakım onarım işlemlerini gerçekleştiren, bağımsız taşeron (ikinci yüklenici) firmadır. Otomobil yetkili servisleri, otomobil firmasıyla yaptıkları anlaşmalar kapsamında, garanti süresi ve şartları dahilinde olan otomobillere ücretsiz; garanti süresi ve kapsamı dışında olan otomobillere ise, ücretli olarak hizmet sunmaktadır (Bengül, 2006). Müşterilerin, otomobil yetkili servisi tercihlerini, sırasıyla, serviste çalışan elemanların tecrübeli olması, serviste yapılan bakım ve onarımlar hakkında müşterilerin yeterince bilgilendirilmeleri, servis fiyatlarının uygun olması, servis esnasında ihtiyaç duyulan yedek parçaların hazır bulundurulması ve aracın garanti kapsamından çıkmaması şeklinde sıralanmaktadır (Karahan ve Dinç, 2016). Otomobil yetkili servisi tercihinde etkili olan faktörler aynı zamanda, müşterilerin aldıkları bakım-onarım hizmeti bileşenlerinin hangilerine ne kadar önem verdiğini göstermektedir. Otomobil yetkili servisi tercihini etkileyen faktörler; bakım-onarım, personelle etkileşim ve fiyat olmak üzere üç boyutta toplanabilir. Benzer şekilde otomobil yetkili servisinden memnuniyeti etkileyen faktörler de, bu üç boyutta toplandığı söylenebilir (Akçay ve Şenol, 2009). Başkalarına tavsiye etme davranışı, literatürde yaygın olarak müşteri sadakatinin ve ağızdan ağıza pazarlamanın göstergesi olarak değerlendirilmektedir (Keskin ve Cepni, 2012; Yazgan ve diğ., 2014). Literatürde memnuniyetin sadakati ve ağızdan ağıza pazarlama davranışını etkilediğini ortaya koyan çok sayıda çalışmalar vardır (Bayuk ve Küçük, 2007; Çatı ve Koçoğlu, 2008; Yazgan ve diğ., 2014; Öz ve Uyar, 2014). Bu bilgilerden hareketle, otomobil yetkili servislerinde hizmet bileşenlerinden memnuniyet düzeyinin başkalarına tavsiye davranışını etkilediği öngörülebilir. Bu doğrultuda geliştirilen hipotez aşağıdadır.

$H_{1}$ : Otomotiv yetkili servislerinde hizmet bileşenlerinden memnuniyet düzeyi başkalarına tavsiye davranışını istatistiksel olarak anlamlı bir şekilde etkilemektedir.

\section{YÖNTEM}

Araştırma nicel araştırma yöntemine göre tasarlanmıştır. Araştırmanın evreninin Düzce'de bulunan bir otomobil yetkili servisinden (HASMER) hizmet alan müşteriler oluşturmaktadır. Araştırma kapsamında veriler anket yöntemiyle toplanmıştır. Anket formu, hizmet satın alan kişiye yönelik demografik bilgiler, yetkili serviste sunulan hizmetin bileşenlerinden memnuniyet düzeyi ve başkalarına tavsiye etme davranışına ilişkin soruları içermektedir. Otomobil yetkili servislerindeki hizmet bileşenlerinin belirlenmesi ve bu bileşenlere ilişkin ölçek geliştirme süreçlerinde bir otomobil yetkili servisiyle iş birliğine gidilmiştir. Geliştirilen bu ölçek, beşli Likert ölçeği olup, 10 ifadeden oluşmaktadır. Araştırmanın bağımlı değişkeni olan başkalarına tavsiye davranışı bir ifade ile ölçülmüştür. Katılımcılara, hizmet aldıkları Hasmer bayisini arkadaşlarına ya da tanıdıklarına tavsiye edip etme durumları beş cevap seçeneğiyle (1: kesinlikle tavsiye etmem... 5: kesinlikle tavsiye ederim)sorulmuştur. Oluşturulan anket formu ile belirtilen yetkili servisten hizmet alan 100 kişiden veri toplanmıştır. Toplanan veriler, sosyal bilimler için istatistiksel paket programı aracılığıyla ve yapısal eşitlik modellemesi ile analiz edilmiştir. Verilerin analizinde faktör analizi, güvenilirlik analizi, regresyon analizi ve yol analizi kullanılmıştır. 


\section{BULGULAR VE TARTIŞMA}

Otomobil yetkili servislerinde sunulan hizmetin üç bileşeni bulunmaktadır. Bunlardan birincisi, sunulan bakım-onarım hizmeti; ikincisi, bakım onarım sürecinde personel ile etkileşim (müşteri danışmanı); üçüncüsü ise, fiyattır. Ölçekte yer alan ifadelerden iki tanesi fiyat, beş üç tanesi müşteri danışmanı ve beş tanesi ise bakım-onarım sürecine ilişkin hizmet bileşenleridir. Hizmet bileşenlerinden memnuniyet düzeyini ölçmek için kullanılan ölçekten elde edilen verileri özetlemek için faktör analizi uygulanmıştır. Analiz sonucunda, aşağıdaki tabloda gösterilen sonuçlara ulaşıımıştır.

Tablo 1: Faktör ve Güvenilirlik Analizi Sonuçları

\begin{tabular}{|c|c|c|c|c|c|}
\hline & 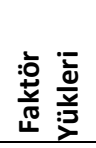 & $\frac{\stackrel{\pi}{E}}{\frac{\pi}{\pi}}$ & 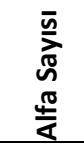 & 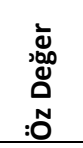 & 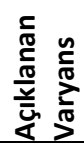 \\
\hline Bakım Onarım & & 3,96 & 0,94 & 3,73 & 46,64 \\
\hline Serviste geçen süreden memnuniyet & 0,90 & 3,84 & & & \\
\hline Yedek parça bulunabilirliğinden memnuniyet & 0,84 & 3,58 & & & \\
\hline $\begin{array}{l}\text { Aracın yetkili servise teslimi sırasındaki } \\
\text { işlemlerin hızlı ve eksiksiz yapılmasından } \\
\text { memnuniyet }\end{array}$ & 0,79 & 4,11 & & & \\
\hline $\begin{array}{l}\text { Belirtilen sürede bakım/onarımın tamamlanıp } \\
\text { aracın teslim edilmesinden memnuniyet }\end{array}$ & 0,76 & 4,33 & & & \\
\hline $\begin{array}{l}\text { Servis sonrasında aracın teslimat sürecinden } \\
\text { memnuniyet }\end{array}$ & 0,75 & 3,94 & & & \\
\hline Müşteri Danışmanı & & 4,31 & 0,98 & 3,33 & 41,62 \\
\hline $\begin{array}{l}\text { Illgilenen müşteri danışmanından genel } \\
\text { memnuniyet }\end{array}$ & 0,92 & 4,32 & & & \\
\hline $\begin{array}{l}\text { Müşteri danışmanının tecrübesi ve } \\
\text { uzmanlığından memnuniyet }\end{array}$ & 0,91 & 4,27 & & & \\
\hline $\begin{array}{l}\text { Müşteri danışmanının güler yüzlülüğünden ve } \\
\text { yardımcı olmaya istekli olmasından memnuniyet }\end{array}$ & 0,91 & 4,35 & & & \\
\hline
\end{tabular}

Faktör çıkarma metodu: Temel bileşenler analizi; Döndürme metodu: Verimax; Toplam Açıklanan Varyans: 0,88; KMO Örneklem Yeterliliği: \%90; Bartlett's Küresellik Testi için Ki-Kare:1112,62 $\mathrm{p}=0,000<0.001 ;$ Alfa Sayısı: 0,96

Faktör analizi sonucunda, hizmet kalitesi bileşenlerinden olan fiyat ile ilgili iki ifade ve bakım onarım ile ilgili bir ifade ölçekten çıkarılmış ve kalan yedi ifade iki boyut altında toplanmıştır. Bu boyutlardan birincisi, bakım-onarım süreci ile ilgili ifadeleri barındırdığı için bu faktör bakım onarım; ikincisi ise müşteri danışmanı ile iletişim ve etkileşim ile ilgili ifadeleri barındırdığı için bu faktöre de müşteri danışmanı ismi verilmiştir. Yukarıdaki tabloda gösterilen değerlerden hareketle, veri setinin faktör analizine uygun olduğu ve örneklem büyüklüğünün yeterli olduğu söylenebilir. Ayrıca, ifadelere ilişkin faktör yüklerinin 0,75 ve üzeri olması da veri özetleme sürecinin geçerliliğine işaret etmektedir. Bunun yanına, ölçeğin güvenilirliğine ilişkin Cronbach alfa sayısı, ölçeğin yüksek derecede güvenilir olduğu anlamına gelmektedir. Ölçekte yer alan ",aracınızda gerçekleştirilen bakım ve onarım işlemlerinin kalitesinden memnuniyet düzeyi” (ortalama: 4,35) ifadesi ve "teslimatta başlangıçta verilen tahmini fiyata sadık kalınmasından memnuniyet düzeyi" (ortalama: 4,36) ifadeleri her iki faktörde de 0,60 ve üzeri faktör yüküne sahip olmaları dolayısıyla faktör analizinden çıkarılmıştır. Ayrıca, "bakım ve onarım fiyatlarından memnuniyet düzeyi" (ortalama: 3,08 ) ifadesi de düşük faktör yükü dolayısıyla ölçekten çıkarılmış ve yukarıda tabloda gösterilen sonuçlara ulaşılmıştır. Araştırmada bağımlı değişken olan başkalarına tavsiye etme davranışının aritmetik ortalaması 4.22 ve standart sapması ise, 1,12' dir. Bu değer, genel olarak müşterilerin çevrelerindeki kişilere Hasmer bayisini tavsiye ettikleri anlamına gelmektedir.

Bakım-onarım hizmetinden ve müşteri danışmanından memnuniyet düzeyinin başkalarına tavsiye üzerindeki etkisini test etmek için çoklu regresyon analizi gerçekleştirilmiştir. Regresyon analizi Enter modeliyle gerçekleştirilmiştir. Analizi sonucunda, düzeltilmiş R2 değeri 0,77 çıkmıştır. Bu değer, bağımsız değişkenler olan bakım onarım ve müşteri danışmanı hizmetlerinden memnuniyetin başkalarına tavsiye davranışının \%77'sini açıkladığı anlamına gelmektedir. Ayrıca, ANOVA analizinde $\mathrm{F}$ değerinin $(0,00)$ anlamlı çıkması, modelin kabul edilebilir bir model olduğu anlamına gelmektedir. Analiz sonucuna göre; bakım oranım hizmetinden memnuniyetteki bir birimlik değişim başkalarına tavsiye etmede 0,58 birimlik değişime; personel ile iletişimdeki bir birimlik değişim başkalarına tavsiye etmede 0,66 birimlik bir değişime neden 
olmaktadır. Bu bilgilerden hareketle, hem personel ile iletişimden memnuniyetin hem de bakım onarım hizmetlerinden memnuniyetin başkalarına tavsiye etmeyi yüksek oranda etkilediği söylenebilir. Regresyon analizinin sonuçları Tablo 2'de gösterilmiştir.

Tablo 2: Enter Modeli Regresyon Analizi Sonucu

\begin{tabular}{|l|c|c|c|}
\hline & $\begin{array}{c}\text { Standartlaştırılmış } \\
\text { Beta }\end{array}$ & t & Sig. \\
\hline Sabit Katsayı & 4,22 & 76,58 & 0,00 \\
Bakım-Onarım & 0,58 & 11,61 & 0,00 \\
Müşteri Danışmanı & 0,65 & 13,19 & 0,00 \\
\hline
\end{tabular}

Bağımlı Değişken: Başkalarına tavsiye davranışı; Düzeltilmiş R²: 0,77; Durbin-Watson değeri:

1,66; Modelin Anlamlılığını gösteren ANOVA testi F değerinin Anlamlılık düzeyi: 0,00

Hizmet kalitesinin ölçmek için kullanılan ölçeğe faktör analizi uygulandığı ve fiyat değişkenine ait ifadelerin ölçekten çıkartıldığı yukarıda ifade edilmişti. Bu nedenle, yukarıda enter modeline göre gerçekleştirilen regresyon analizi fiyattan memnuniyetin başkalarına tavsiye davranışı üzerindeki etkisini kapsamamaktadır. Fiyat ile ilgili bileşenlerin başkalarına tavsiye davranışı üzerindeki etkisini görebilmek adına, veri seti basamaklı regresyon analizi ile analiz edilmiştir. Basamaklı regresyonun amacı, çok sayıda bağımsız değişkenin içinden bağımlı değişkeni en iyi açıklayan ve aralarında otokorelasyon olmayan azami sayıda bağımsız değişkeni seçmektir. Hizmet kalitesi bileşenlerini ölçmek için geliştirilen 10 ifadenin tamamı bağımsız değişken olarak ve başkalarına tavsiye davranışı ise, bağımlı değişken olarak analize tabi tutulmuştur. Tablo 3 'te gösterildiği gibi, hizmet bileşenlerinden üç tanesi başkalarına tavsiye davranışının 0,78'ini açıklamaktadır. Ayrıca, ANOVA analizinde $\mathrm{F}$ değerinin $(0,00)$ anlamlı çıkması, modelin kabul edilebilir bir model olduğunu göstermektedir.

Analiz sonuçlarına göre, "teslimatta, başlangıçta verilen fiyata sadık kalma" başkalarına tavsiye etmeyi en çok etkileyen değişkendir. Bunun yanında, basamaklı regresyon analizi sonuçlarına göre, "genel olarak müşteri ile ilgilenen müşteri danışmanından memnuniyet" ve "aracın yetkili servise teslimi sırasındaki işlemlerin hızlı ve eksiksiz yapılmasından memnuniyet" başkalarına tavsiye etmeyi en çok etkileyen faktörlerdir. Bu durum, araştırmaya dahil edilen diğer hizmet kalitesi bileşenlerinin başkaları tavsiye üzerinde etkili olmadığı veya çok az etkili olduğu anlamına gelmemektedir. Bunun yerine, ortaya çıkan bu sonuç, aralarında yüksek korelasyon olmayan hizmet bileşenleri içerisinden başkalarına tavsiye davranışını en çok etkileyen bileşenleri göstermektedir. Örneğin, müşteri danışmanı ile ilgili diğer ifadeler de başkalarına tavsiyeyi etkileyebilir. Fakat burada, diğer değişkenlerin müşteri danışmanından genel memnuniyet düzeyi arasındaki korelasyon olması dolayısıyla basamaklı regresyon analizi sadece genel memnuniyet düzeyini buraya alarak otokorelasyona engel olmuştur. Buradaki bir ifadenin müşteri danışmanı ile ilgili ifadeleri ve diğer ifadenin ise bakım onarım ile ilgili ifadeleri temsil ettiği faktör analizi sonuçlarından hareketle söylenebilir. Buradaki diğer bir önemli bir sonuç ise, "teslimatta, başlangıçta verilen fiyata sadık kalma" ifadesinin diğer bakım -onarım ile ilgili ifadelerden daha fazla başkalarına tavsiye etme değişkenini etkilemesidir. Bu sonuçlardan hareketle, müşterilerin başkalarına tavsiye davranışının en çok müşteri ile ilgilenen müşteri danışmanından ve teslimatta, başlangıçta verilen fiyata sadık kalma durumundan memnuniyet düzeyinden etkilendiği söylenebilir.

Tablo 3: Basamaklı Regresyon Analizi Sonuçları

\begin{tabular}{|l|c|c|c|}
\hline & Standartlaştırılmış Beta & t & Sig. \\
\hline Sabit Katsayı & $-1,08$ & $-3,78$ & 0,00 \\
$\begin{array}{l}\text { Teslimatta başlangıçta verilen tahmini fiyata sadık } \\
\text { kalınmasından memnuniyet düzeyi }\end{array}$ & 0,39 & 4,66 & 0,00 \\
$\begin{array}{l}\text { Genel olarak, sizinle ilgilenen müşteri danışmanından } \\
\text { memnuniyet düzeyi }\end{array}$ & 0,37 & 5,07 & 0,00 \\
$\begin{array}{l}\text { Aracın yetkili servise teslimi sırasındaki işlemlerin hızlı } \\
\text { ve eksiksiz yapıımasından memnuniyet düzeyi }\end{array}$ & 0,22 & 0,00 \\
\hline
\end{tabular}

Araştırmada, başkalarına tavsiyeyi etkileyen hizmet bileşenlerinin bir arada ve kapsamlı şekilde değerlendirmek adına yapısal eşitlik modellemesi kullanılmış ve aşağıdaki model test edilmiştir. Tablo 4'te de gösterildiği gibi, model genel olarak iyi uyum değerlerine sahiptir. 
Tablo 4: Model Uyum Indeksleri

\begin{tabular}{lcccc}
\hline & $\begin{array}{c}\text { Uyum } \\
\text { istatistiği }\end{array}$ & İyi Uyum & $\begin{array}{c}\text { Kabul Edilebilir } \\
\text { Uyum }\end{array}$ & $\begin{array}{c}\text { Modelde } \\
\text { Ait Değer }\end{array}$ \\
\hline $\begin{array}{l}\text { Genel Model } \\
\text { Uyumu }\end{array}$ & $\mathrm{X}^{2}$ & $0,05-1,00$ & $\leq 0,05$ & 0,001 \\
\hline & $\mathrm{X}^{2} / \mathrm{sd}$ & $\leq 3$ & $\leq 4-5$ & 2.048 \\
\hline Karşılaştırmalı & $\mathrm{NFI}$ & $\geq 0,95$ & $0,94-0,90$ & 0,96 \\
Uyum Indeksleri & $\mathrm{IFI}$ & $\geq 0,95$ & $0,94-0,90$ & 0,98 \\
& $\mathrm{CFI}$ & $\geq 0,97$ & $\geq 0,95$ & 0,98 \\
\hline Mutlak uyum & $\mathrm{RMSEA}$ & $\leq 0,5$ & $0,6-0,8$ & 0,17 \\
Indeksleri & $\mathrm{GFI}$ & $\geq 90$ & $0,89-0,85$ & 0,91 \\
\hline
\end{tabular}

Analiz sonucuna göre, bakım onarım hizmetlerinden (BOS) memnuniyet ile müşteri danışmanından memnuniyet (MD) arasında kuvvetli bir ilişki vardır. Ayrıca, bakım onarımdan memnuniyet ve müşteri danışmanından memnuniyetin başlangıçta verilen fiyata sadık kalma (BVFSK) ile yüksek; bakım onarım fiyatı (BOFY) ile aralarında orta düzeyde bir ilişkisi vardır.

Şekil 1: Yapısal Eşitlik Modellemesi Sonuçları

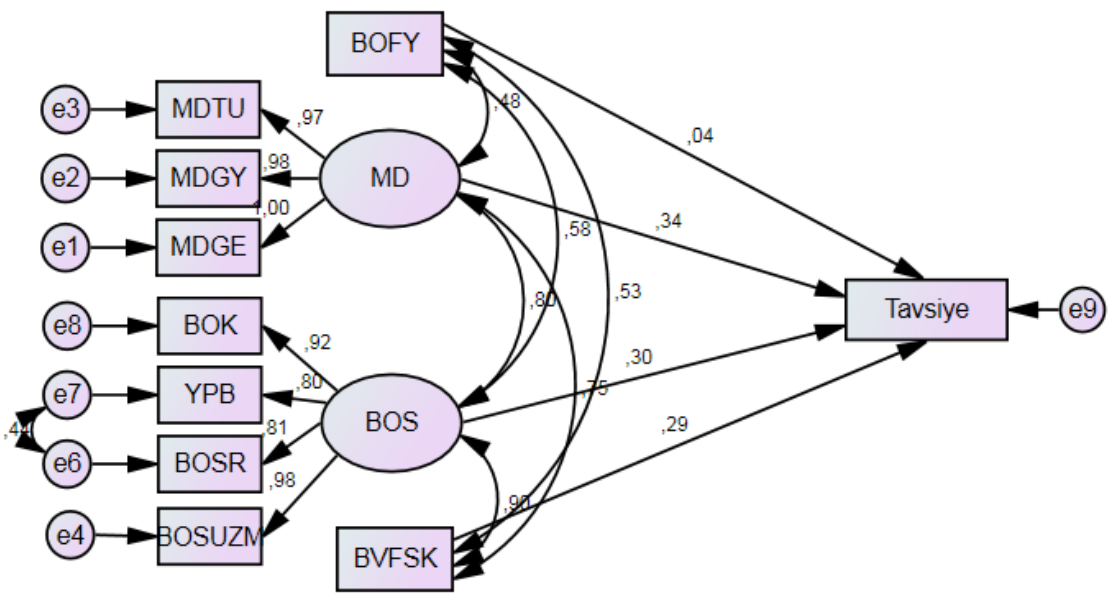

Şekil 1'deki modelde görüldüğü gibi, başkalarına tavsiyeyi en çok etkileyen değişken müşteri danışmanından memnuniyet değişkenidir. Bunun yanında, bakım onarım hizmetinden memnuniyet ve başlangıçta verilen fiyata sadık kalma değişkenleri başkalarına tavsiyeyi hemen hemen müşteri danışmanından memnuniyet değişkeni kadar etkileyen diğer değişkenlerdir. Ayrıca, bakım onarım hizmetinin fiyatı, başkalarına tavsiye değişkenini istatistiksel olarak anlamlı bir şekilde etkilememektedir $(0,49>0,05)$. Bu sonuç, beklentilerle kısmen örtüşmekte ve kısmen de ters düşmektedir. Çünkü ifadelere ilişkin ortalamalar değerlendirildiğinde, en az memnun olunan hizmet bileşenini bakım onarım hizmetinin fiyatı olduğu gözükmektedir $(3,08)$. Bu bilgiden hareketle fiyatların müşteriler için kısmen yüksek olduğu sonucuna varılabilir. Bundan hareketle fiyatın tavsiye üzerinde etkisininim olmaması veya negatif etkisinin olması beklenen bir sonuç olarak değerlendirilmektedir

\section{SONUÇ}

Araştırma sonucuna göre, müşteri danışmanından memnuniyet, bakım onarım hizmetinden memnuniyet ve başlangıçta verilen fiyata sadık kalma başkalarına tavsiye etme değişkenini büyük oranda açıklayan faktörlerdir. Bu sonuçlar Özgüner ve Kurtuldu (2015) ve Karahan ve Dinç (2016) tarafından gerçekleştirilen çalışmanın sonuçlarıyla örtüşmektedir. Özgüner ve Kurtuldu (2015) tarafından yapılan çalışmada otomobil yetkili sevişlerindeki teknik bilgilendirme ve bakım-onarım hizmetlerinin müşteri memnuniyetini yüksek düzeyde etkilediği sonucuna ulaşılmıştır. Karahan ve Dinç (2016) tarafından yapılan çalışmanın sonucunda ise, bakım-onarım ve müşteri danışmanı ile iletişim süreçlerinin müşteri tercihlerine etkisi üzerinde durulmuştur. Bu çalışmada ise, bu iki önemli boyutun yanında, başlangıçta verilen fiyata sadık kalmanın başkalarına tavsiye üzerindeki etkisi ortay konmuştur. 
Otomobil yetkili servislerindeki bakım onarım hizmeti, teknik bir hizmettir. Bu hizmetten faydalananlar, hizmetin teknik boyutunu net olarak değerlendirmeyebilmektedir. Bunun yanında, müşteri danışmanı ile iletişim ve başlangıçta verilen fiyata sadık kalma, müşteriler tarafından daha net değerlendirilebilmektedir. Ayrıca, teknik çözümler kolaylıkla kopyalanabilirken, çalışan-müşteri ilişkilerine odaklanarak rakiplere üstünlük sağlamak, rakiplere tarafından nispeten daha zor kopyalanabilmektedir (Sweeney ve diğ., Johnson, 1997). Dahası, satış sonrası müşteri hizmetleri, müşteri tatmini açısından önemli rekabet araçlarından biridir (Güllülü ve Bilgili, 2011).Bu doğrultuda, otomobil yetkili servislerine, özellikle başlangıçta fiyat verirken bütün masraf kalemlerini net olarak belirlemeleri ve araç tesliminde bu fiyata sadık kalmaları tavsiye edilmektedir. Ayrıca, otomobil yetkili servislerine, müşterilerin teknik bir konu olan bakım onarımı net değerlendirememeleri ve bakım onarımı müşteri temsilcileri ile olan iletişim üzerinden değerlendirmeleri dolayısıyla, müşteri danışmanlarının tecrübeli, bakım onarımla ilgili uzmanlığı olan, güler yüzlü ve yardımcı olmaya istekli kişileri müşteri danışmanı olarak çalıştırmaları tavsiye edilmektedir. Bu çalışmada ulaşılan bir diğer önemli sonuç daha vardır. Katılımcıların en az memnun olduğu hizmet bileşenini fiyat olmasına rağmen, katılımcılar genel olarak işletmeyi başkalarına tavsiye etmektedir. Dahası, fiyattan düşük memnuniyet düzeyi, başkalarına tavsiye davranışını negatif yönde etkilememektedir. Bu durum, teknik hizmet sunan otomobil yetkili servislerinin, müşteri danışmanı, bakım-onarım ve başlangıçta verilen fiyata sadık kalma ile ilgili müşteri memnuniyetini sağlamaları halinde, fiyat üzerinde değişikliklere gidebilecekleri anlamına gelmektedir. Bu doğrultuda otomobil yetkili servislerine, fiyatın başkalarına tavsiyede bir kriter olmamasından hareketle, maliyetlerden ziyade, hizmet sundukları bölgedeki rekabete bağımlı olarak fiyatı belirlemeleri tavsiye edilmektedir.

\section{KAYNAKLAR}

Akçay, M., Şenol, O. (2009). Otomotiv Yetkili Servis Diş Müşterilerinin Memnuniyet Düzeylerine Etki Eden Faktörler Üzerine Bir Alan Araştırması. Selçuk-Teknik Dergisi, 8(1), 30-47.

Bayuk, M. N., Küçük, F. (2007). Müşteri tatmini ve müşteri sadakati ilişkisi, Marmara Üniversitesi i.I.B.F. Dergisi, 22 (1), $285-292$.

Bengül, S. (2006). Satış Sonrası Müşteri Hizmetlerinin Marka Bağlılığı Üzerindeki Etkisi: Beyaz Eşya Kullanıcıları Üzerinde Bir Araştırma ve Yapısal Bir Marka Bağlılık Modeli Önerisi, Yayınlanmamış Yüksek Lisans Tezi, Isparta: Dumlupınar Üniversitesi Sosyal Bilimler Enstitüsü.

Çatı, K., Koçoğlu, C. M. (2008). Müşteri Sadakati ile Müşteri Tatmini Arasındaki iliş̧kiyi Belirlemeye Yönelik Bir Araştırma. Selcuk University Social Sciences Institute Journal, 19, 167-188.

Güllülü, U. Bilgili, B. (2011). Satış sonrası hizmetlerde kalite algısı ve müşteri memnuniyeti ilişkileri. Pazarlama ve Pazarlama Araştırmaları Dergisi, 7, 23-41.

Karahan, M., Dinç, H. (2016). Otomobil Bakim ve Servis Hizmetleri Tercihine Etki Eden Faktörlerin Belirlenmesi, MANAS Sosyal Araştırmalar Dergisi, 5 (3), 199-214.

Keskin, D., Çepni, B. (2012). Ağızdan Ağıza Pazarlama Kapsamında Demografik ve Sosyal Faktörlerin Üniversite Öğrencilerinin Sinema Filmi Tercihleri Üzerindeki Etkilerinin Belirlenmesi. Uluslararası Yönetim İktisat ve İşletme Dergisi, 8 (16), 99-117.

Öz, M., Uyar, E. (2014). Sağlık Hizmetleri Pazarlamasında Algılanan Hizmet Kalitesi ve Müşteri Memnuniyeti Üzerinde Ağızdan Ağıza Pazarlamanın Etkisini Belirlemeye Yönelik Bir Araştırma. KMÜ Sosyal ve Ekonomik Araştırmalar Dergisi, 16 (26), $123-132$.

Özbek, V . (2016). Algılanan Risk Ve Algılanan Değer Arasındaki Ilişkide Algılanan Hizmet Kalitesinin Düzenleyici Etkisi. International Review of Economics and Management, 4 (3), 62-83. DOI: 10.18825/irem.91601

Özgüner, Z. Kurtuldu, H.S. (2015). Yetkili servislerde verilen satış sonrası hizmetlerin, müşteri memnuniyetine etkisi: İstanbul ili otomotiv sektöründe bir uygulama. Çankırı Karatekin Üniversitesi iïF Dergisi, 2: 569-589, http://dx.doi.org/10.18074/cnuiibf.237.

Sweeney, J.C., Soutar, G.N., Johnson, L.W. (1997). Retail service quality and perceived value a comparison of two models. Journal of Retailing and Consumer Services, 4 (1), 39-48

Sweeney, J.C., Soutar, G.N., Johnson, L.W. (1999). The role of perceived risk in the quality-value relationship: a study in a retail environment. Journal of Retailing, 75 (1), 77-105.

Yazgan, H.í., Kethüda, Ö., Kahraman, Ç. (2014). Tüketici Temelli Marka Değerinin Ağızdan Ağza Pazarlamaya Etkisi, C.Ü. İktisadi ve İdari Bilimler Dergisi, 15 (1), 237-252.

Yee, C.J., San, N.C., Khoon, C.H. (2011). Consumers' perceived quality, perceived value and perceived risk towards purchase decision on automobile. American Journal of Economics and Business Administration, 3(1), 47-57. 